\title{
Predictors of Suicidal Ideation and Attempt among Patients with Major Depressive Disorder at a Tertiary Care Hospital, Puducherry
}

\author{
Ralte Lalthankimi ${ }^{1}$ Padmavathi Nagarajan ${ }^{1} \quad$ Vikas Menon $^{2} \quad$ Jeby Jose Olickal ${ }^{3}$ \\ ${ }^{1}$ College of Nursing (Psychiatric Nursing), Jawaharlal Institute of \\ Post Graduate Medical Education and Research, Puducherry, India \\ 2Department of Psychiatry, Jawaharlal Institute of Post Graduate \\ Medical Education and Research, Puducherry, India

\begin{abstract}
Address for correspondence Jeby Jose Olickal, PhD, Department of Preventive and Social Medicine, Jawaharlal Institute of Post Graduate Medical Education and Research, Puducherry, India (e-mail: drjebyjose@gmail.com).
\end{abstract}

${ }^{3}$ Department of Preventive and Social Medicine, Jawaharlal Institute of Post Graduate Medical Education and Research, Puducherry, India

J Neurosci Rural Pract:2021;12:122-128

\begin{abstract}
Keywords

- depression

- suicide

- behaviors

- psychiatry

Objectives Mental disorders have a large impact on death by suicide. Hence, this study aims to determine the prevalence of suicidal behaviors among major depressive disorder (MDD) patients and the associated factors.

Materials and Methods This cross-sectional analytical study was conducted among individuals aged 18 to 65 years, diagnosed with MDD in the Psychiatry Outpatient Department of a Tertiary Care Center, Puducherry during March to October 2019. Severity of depression was assessed using Hamilton Depression Rating Scale and Columbia-Suicide Severity Rating Scale was used to find the suicidal behaviors.

Results For 166 participants in the study, mean (standard deviation) age was 40 (11) years and majority were females (76\%). More than one-third (37\%) had severe or very severe depression, and the prevalence of suicidal ideation, plan, and attempts were 83,24 , and $35 \%$, respectively. After adjusting the covariates, the severity of depression and unemployment were significantly associated with suicidal attempts (adjusted prevalence ratios [aPR] = 11.4 and 1.9), and very severe depression was associated with suicidal ideation ( $\mathrm{aPR}=1.6)$. Among 140 individuals with suicidal ideation, $45(32 \%)$ had an ideation frequency of 2 to 3 times/week, 69 (50\%) had ideation for 1 hour, 36 (26\%) could control ideation with little difficulty, and $12 \%$ had suicidal ideation mostly to end or stop their pain.

Conclusion Suicidal ideation and attempts were significantly high in MDD patients, and the severity of depression was significantly associated with it. Early identification of high-risk suicidal behavior and implementation of effective preventive interventions are necessary to reduce death by suicide in these groups.
\end{abstract}

DOI https://doi.org/

$10.1055 / \mathrm{s}-0040-1721558$

ISSN 0976-3147. (c) 2021. Association for Helping Neurosurgical Sick People.

This is an open access article published by Thieme under the terms of the Creative Commons Attribution-NonDerivative-NonCommercial-License, permitting copying and reproduction so long as the original work is given appropriate credit. Contents may not be used for commercial purposes, or adapted, remixed, transformed or built upon. (https://creativecommons.org/licenses/by-nc-nd/4.0/).

Thieme Medical and Scientific Publishers Pvt. Ltd. A-12, 2nd Floor, Sector 2, Noida-201301 UP, India 


\section{Introduction}

According to World Health Organization (WHO) every year, almost a million people die from suicide and the mortality rate of 16 per 100,000 or one death every 40 seconds. ${ }^{1}$ In both developed and developing countries, it is one of the $10 \mathrm{com}-$ mon reasons of death among youth and adults. ${ }^{2}$ Over 130,000 people die from suicide every year in India. ${ }^{3}$ The prevalence of depression ranges from 0.1 to $6.94 \%$ in community studies and 1.2 to $21 \%$ in clinic-based studies ${ }^{4}$

Studies from Western populations showed that mental disorders have a large impact on death by suicide. At the time of suicide, approximately 9 out of 10 individuals seemed to have some mental disorder. ${ }^{5}$ The incidence of suicide among individuals with major depressive disorder (MDD) is significant, and suicide is one of the most worrying outcomes of depression. Among all the outcomes of depression, suicide is obviously the end consequence of a person's feeling of hopelessness, worthlessness, and incapacity. Although it is well known that people also commit suicide for different reasons besides depression, depressed people are at a higher risk of death by suicide. ${ }^{6}$

Researchers have identified many risk factors for suicide attempts in the community; however, many had failed to identify the same among MMD patients.7 Understanding predictors of suicidal ideation among MMD patients is also important because these factors predict future attempts. ${ }^{8-12}$ Since depression usually has an association with suicidal behavior, a continuous focus on assessing the risk related to these issues should be a major concern in managing patients with depression. Hence, the current study aimed to determine the prevalence of suicidal behaviors among MDD patients and the factors associated with it.

\section{Materials and Methods}

This cross-sectional analytical study was conducted in the Psychiatry Outpatient Department of a Tertiary Care Center, Puducherry, South India from March to October 2019. Individuals aged 18 to 65 years diagnosed with MDD as per International Classification of Diseases-10 criteria were included. This tertiary care institute provides health care to people from the union territory of Puducherry and also its neighboring districts from Tamil Nadu and Andhra Pradesh. Assuming the prevalence of suicidal ideation ever among individuals with MDD as $88 \%$, with an absolute precision of 5 and $95 \%$ confidence level, the calculated sample size for the study was 166 . The sample size was calculated using OpenEpi version 3.03 .

All individuals with MDD who sought care during August to October 2019 were approached for study until the required sample size was achieved. Individuals with acute medical illnesses or diagnoses as mental retardation were excluded. Participants were interviewed using a validated structured questionnaire for sociodemographic details. Hamilton Depression Rating Scale (HAM-D) and Columbia-Suicide Severity Rating Scale (C-SSRS) were used to collect data on the level or severity of depression and suicidal behavior (ideation, plans, and attempts), respectively. Questionnaires were translated into Tamil and back-translated into English to check for language validity.

HAM-D is a 21-item scale questionnaire, whereas the scoring is based on the first 17 items. Of them, eight items were 5 -point scale, alternating from 0 as "not present" to 4 as "severe." The other nine items were scored from 0 to 2 . A total score of more than 23 was considered as "very severe depression," score from 19 to 22 as "severe depression," 14 to 18 as "moderate depression," 8 to 13 as "mild depression," and a score less than 8 was considered "normal." The C-SSRS consists of 10 categories, all of which contain two responses (yes/no) to denote the presence or absence of suicidal behavior. A thought or wish to die by taking one's own life or killing oneself as assessed by C-SSRS was defined as "suicidal ideation" for this study. An action in which a person tried ending one's own life but failed to complete it, or harming themself or doing anything that is dangerous where he/she could have died was referred to as "suicidal attempt."

The study protocol was reviewed and approved by the Nursing Research Monitoring Committee and Institute Ethics Committee. Written informed consent was taken before enrolling the study participants.

Data were entered into Microsoft Excel and analyzed using Stata software version 14 (Statacorp., Texas, United States). Suicidal ideation, plan, and attempts were expressed as proportions with $95 \%$ confidence intervals $(\mathrm{CI})$. Association of sociodemographic characteristics with suicidal ideation and attempts was assessed using Chi-square test and unadjusted prevalence ratios with $95 \% \mathrm{CI}$ were calculated. We used log-binomial model with suicidal ideation/attempts as outcome variable by including the variables having a $p$-value less than 0.2 in unadjusted analysis, and adjusted prevalence ratios with $95 \%$ CIs were calculated. A p-value of less than 0.05 was considered statistically significant.

\section{Results}

A total of 166 individuals with MDD participated. Mean (standard deviation) age of the participants was 40 (11) years. Majority were females (76\%) and married (80\%). In total, $26(16 \%)$ had no formal education, and 119 (72\%) were unemployed. Most of the participants belonged to nuclear family (80\%) and $94 \%$ had a history of psychiatric illness. More than one-third (37\%) had severe or very severe depression (-Table 1).

The prevalence of suicidal ideation, plan, and attempt was 83,24 , and $35 \%$, respectively ( - Fig. 1). Women ( $\mathrm{CPR}=1.07$ ), those who were unmarried (crude prevalence ratios [CPR] $=1.30)$, having studied up to higher secondary school (cPR $=1.25)$, belonging to nuclear family $(\mathrm{CPR}=1.09)$, having a history of psychiatric illness ( $c P R=1.73$ ) and under very severe depression ( $\mathrm{CPR}=1.63$ ) were reported to have a higher prevalence of suicidal ideation compared with their counterparts ( - Table 2 ). After adjusting the covariates, the severity of depression was significantly associated with suicidal ideation. 
Table 1 Sociodemographic factors and severity of depression among individuals with major depressive disorder at a tertiary care hospital, Puducherry $(n=166)$

\begin{tabular}{|c|c|c|c|}
\hline Variables & Categories & $n$ & $\%$ \\
\hline \multirow[t]{2}{*}{ Gender } & Male & 40 & 24.1 \\
\hline & Female & 126 & 75.9 \\
\hline \multirow[t]{4}{*}{ Age (y) } & $18-29$ & 28 & 16.9 \\
\hline & $30-44$ & 78 & 47 \\
\hline & $45-59$ & 51 & 30.7 \\
\hline & $\geq 60$ & 9 & 5.4 \\
\hline \multirow[t]{3}{*}{ Marital status } & Single & 30 & 18.1 \\
\hline & Married & 133 & 80.1 \\
\hline & Divorced/widowed & 3 & 1.8 \\
\hline \multirow[t]{5}{*}{ No. of children } & No children & 34 & 20.5 \\
\hline & 1 & 24 & 14.5 \\
\hline & 2 & 80 & 48.2 \\
\hline & 3 & 18 & 10.8 \\
\hline & $\geq 4$ & 10 & 6 \\
\hline \multirow[t]{5}{*}{ Education } & No formal education & 26 & 15.7 \\
\hline & Primary & 43 & 25.9 \\
\hline & High school & 61 & 36.8 \\
\hline & Higher secondary & 13 & 7.8 \\
\hline & Graduate and above & 23 & 13.9 \\
\hline \multirow[t]{2}{*}{ Employment status } & Employed & 47 & 28.3 \\
\hline & Currently unemployed & 119 & 71.7 \\
\hline \multirow[t]{2}{*}{ Type of family } & Nuclear & 133 & 80.1 \\
\hline & Joint/extended & 33 & 19.9 \\
\hline \multirow[t]{2}{*}{ History of psychiatric illness } & Yes & 156 & 94 \\
\hline & No & 10 & 6 \\
\hline \multirow[t]{4}{*}{ Severity of depression } & Mild & 41 & 24.7 \\
\hline & Moderate & 63 & 38.0 \\
\hline & Severe & 30 & 18.1 \\
\hline & Very severe & 31 & 18.7 \\
\hline
\end{tabular}

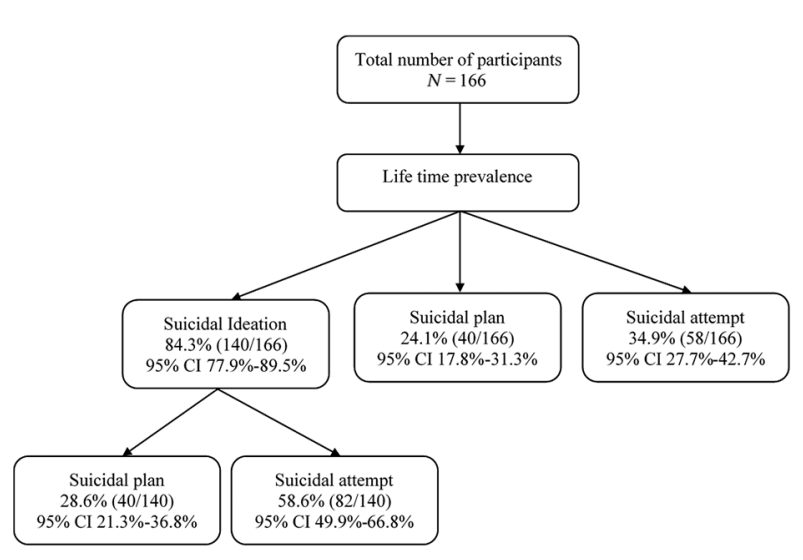

Fig. 1 Flow chart depicting suicidal ideation, plan, and attempts among individuals with major depressive disorder at a tertiary care hospital, Puducherry.
The prevalence of suicidal attempts was higher among women $(\mathrm{CPR}=1.36)$, individuals aged between 18 and 30 years $(c P R=1.82)$, married $(c P R=1.31)$, graduated $(c P R=1.53)$, unemployed ( $\mathrm{CPR}=1.69$ ), individuals belonging to nuclear family ( $\mathrm{cPR}=1.06)$, having a history of psychiatric illness ( $\mathrm{cPR}=$ 1.17 ), and under severe depression ( $C P R=11.9$ ). The log-binomial regression analysis showed a higher prevalence of suicidal attempts among the unemployed ( $\mathrm{aPR}=1.87$ ) and among individuals with very severe depression ( $\mathrm{aPR}=11.42$ ) ( - Table 3 ).

The intensity of suicidal ideation as per Columbia Suicide Severity Rating Scale is shown in - Table 4. Among 140 individuals with suicidal ideation, 45 (32\%) had an ideation frequency of 2 to 3 times/week, 69 (50\%) had ideation for 1 hour, and 36 (26\%) could control ideation with little difficulty. Majority (76\%) of the participants did not mention any reason for suicidal ideation and $12 \%$ had suicidal ideation mostly to end or stop their pain. 
Table 2 Univariate and multivariable model (log-binomial) analyses of sociodemographic factors and severity of depression associated with suicidal ideation among individuals with major depressive disorder at a tertiary care hospital, Puducherry $(n=166)$

\begin{tabular}{|c|c|c|c|c|c|}
\hline Variables & Total & $\begin{array}{l}\text { Suicidal ideation } \\
n(\%)\end{array}$ & Crude PR & Adjusted PR & $p$-Value \\
\hline Total & 166 & $140(84.3)$ & & & \\
\hline \multicolumn{6}{|l|}{ Gender } \\
\hline Male & 40 & $32(80.0)$ & 1 & & \\
\hline Female & 126 & $108(85.7)$ & $1.07(0.90-1.27)$ & & \\
\hline \multicolumn{6}{|l|}{ Age $(y)$} \\
\hline $18-29$ & 28 & $22(78.6)$ & 1 & & \\
\hline $30-44$ & 78 & $69(88.5)$ & $1.13(0.91-1.39)$ & & \\
\hline $45-59$ & 51 & $41(80.4)$ & $1.02(0.81-1.30)$ & & \\
\hline$\geq 60$ & 9 & $8(88.9)$ & $1.13(0.84-1.53)$ & & \\
\hline \multicolumn{6}{|l|}{ Marital status } \\
\hline Married & 30 & $23(76.7)$ & $1.15(0.50-2.62)$ & & \\
\hline Unmarried & 133 & $115(86.5)$ & $1.30(0.58-2.90)$ & & \\
\hline Widow & 3 & $2(66.7)$ & 1 & & \\
\hline \multicolumn{6}{|l|}{ Education } \\
\hline No formal education & 26 & $22(84.6)$ & $1.14(0.85-1.53)$ & $1.04(0.85-1.30)$ & 0.675 \\
\hline Primary & 43 & $36(83.7)$ & $1.13(0.86-1.49)$ & $1.01(0.82-1.25)$ & 0.908 \\
\hline High school & 61 & $53(86.9)$ & $1.18(0.90-1.53)$ & $1.20(0.99-1.44)$ & 0.057 \\
\hline Higher secondary & 13 & $12(92.3)$ & $1.25(0.96-1.67)$ & $1.09(0.90-1.31)$ & 0.369 \\
\hline Graduate and above & 23 & $17(73.9)$ & 1 & 1 & \\
\hline \multicolumn{6}{|l|}{ Employment status } \\
\hline Employed & 47 & $40(85.1)$ & $1.01(0.88-1.17)$ & & \\
\hline Currently unemployed & 119 & $100(84.0)$ & 1 & & \\
\hline \multicolumn{6}{|l|}{ Type of family } \\
\hline Nuclear & 133 & $114(85.7)$ & $1.09(0.90-1.32)$ & & \\
\hline Joint/extended & 33 & $26(78.8)$ & 1 & & \\
\hline \multicolumn{6}{|l|}{ History of psychiatric illness } \\
\hline Yes & 156 & $135(86.5)$ & $1.73(0.92-3.23)$ & $1.49(0.86-2.57)$ & 0.155 \\
\hline No & 10 & $5(50.0)$ & 1 & 1 & \\
\hline \multicolumn{6}{|l|}{ Severity of depression } \\
\hline Normal/mild & 42 & $25(59.5)$ & 1 & 1 & \\
\hline Moderate & 63 & $57(90.5)$ & $1.52(1.27-1.97)$ & $1.52(1.20-1.92)$ & 0.001 \\
\hline Severe & 30 & $28(93.3)$ & $1.57(1.20-2.05)$ & $1.54(1.21-1.95)$ & $<0.001$ \\
\hline Very severe & 31 & $30(96.8)$ & $1.63(1.26-2.10)$ & $1.64(1.29-2.08)$ & $<0.001$ \\
\hline
\end{tabular}

Abbreviation: PR, prevalence ratio.

\section{Discussion}

Depression is a chronic mental health issue, which largely plays a significant role in public health and if left untreated would have a high chance of setback. The present study mainly aimed to assess predictors of suicidal ideation and attempts among patients with MDD. Demographic characteristics in the study showed that almost half were aged between 30 and 44 years. It is well understood that people belonging to this group are highly susceptible to have depression due to many stressors in life, which may include marital conflict, unemployment, and health issues. ${ }^{13}$ The obtained results are similar to a study conducted by Yoo et al, ${ }^{14}$ which reported 23.1\% MDD in the age group of 40 to 49 years.

The lifetime prevalence of suicidal ideation (84\% compared with $3.5 \%$ ), plan ( $42 \%$ compared with $0.6 \%$ ) and attempts (35\% compared with $0.3 \%$ ) among MDD was high compared with the findings of National Mental Health Survey, India; the latter being conducted among general population. ${ }^{15}$ Our study findings were similar to a study from United Kingdom where the reported suicidal ideation was $71 \%$ and attempts were $38 \%$ among MDD patients. ${ }^{16}$ In the current study, suicidal ideation was more among females, those who were unmarried, individuals belonging to nuclear family and with 
Table 3 Univariate and multivariable model (log-binomial) analyses of sociodemographic factors and severity of depression associated with suicidal attempts among individuals with major depressive disorder at a tertiary care hospital, Puducherry ( $n=166)$

\begin{tabular}{|c|c|c|c|c|c|}
\hline Variables & Total & $\begin{array}{l}\text { Suicidal } \\
\text { attempt } \\
n(\%)\end{array}$ & Crude PR & Adjusted PR & $p$-Value \\
\hline Total & 166 & $58(34.9)$ & & & \\
\hline \multicolumn{6}{|l|}{ Gender } \\
\hline Male & 40 & $11(27.5)$ & 1 & & \\
\hline Female & 126 & $47(37.3)$ & $1.36(0.78-2.36)$ & & \\
\hline \multicolumn{6}{|l|}{ Age $(y)$} \\
\hline $18-29$ & 28 & $13(46.4)$ & $1.82(0.98-3.37)$ & $1.35(0.74-2.46)$ & 0.333 \\
\hline $30-44$ & 78 & $29(37.2)$ & $1.46(0.84-2.53)$ & $1.37(0.84-2.23)$ & 0.201 \\
\hline $45-59$ & 51 & $13(25.5)$ & 1 & 1 & \\
\hline$\geq 60$ & 9 & $3(33.3)$ & $1.31(0.46-3.69)$ & $1.03(0.38-2.82)$ & 0.949 \\
\hline \multicolumn{6}{|l|}{ Marital status } \\
\hline Married & 30 & $13(43.3)$ & $1.31(0.81-2.11)$ & & \\
\hline Unmarried & 133 & $44(33.1)$ & 1 & & \\
\hline Widow & 3 & $1(33.3)$ & $1.01(0.20-5.08)$ & & \\
\hline \multicolumn{6}{|l|}{ Education } \\
\hline No formal education & 26 & $9(34.6)$ & $1.35(0.64-2.82)$ & $1.38(0.68-2.81)$ & 0.375 \\
\hline Primary & 43 & $11(25.6)$ & 1 & 1 & \\
\hline High school & 61 & $24(39.3)$ & $1.54(0.84-2.79)$ & $1.72(0.96-3.09)$ & 0.069 \\
\hline Higher secondary & 13 & $5(38.5)$ & $1.50(0.64-3.54)$ & $1.81(0.83-3.96)$ & 0.135 \\
\hline Graduate and above & 23 & $9(39.1)$ & $1.53(0.74-3.15)$ & $1.49(0.69-3.21)$ & 0.309 \\
\hline \multicolumn{6}{|l|}{ Employment status } \\
\hline Employed & 47 & $11(23.4)$ & 1 & 1 & \\
\hline Currently unemployed & 119 & $47(39.5)$ & $1.69(0.96-2.96)$ & $1.87(1.09-3.21)$ & 0.023 \\
\hline \multicolumn{6}{|l|}{ Type of family } \\
\hline Nuclear & 133 & $47(35.3)$ & $1.06(0.62-1.81)$ & & \\
\hline Joint/extended & 33 & $11(33.3)$ & 1 & & \\
\hline \multicolumn{6}{|l|}{ History of psychiatric illness } \\
\hline Yes & 156 & $55(35.3)$ & $1.17(0.44-3.10)$ & & \\
\hline No & 10 & $3(30.0)$ & 1 & & \\
\hline \multicolumn{6}{|l|}{ Severity of depression } \\
\hline Normal/mild & 42 & $2(4.8)$ & 1 & 1 & \\
\hline Moderate & 63 & $24(38.1)$ & $8(2.0-32.07)$ & $7.93(1.98-31.76)$ & 0.003 \\
\hline Severe & 30 & $17(56.7)$ & $11.9(2.97-47.69)$ & $11.40(2.83-45.99)$ & 0.001 \\
\hline Very severe & 31 & 15 (34.9) & $10.16(2.50-41.22)$ & $11.42(2.82-46.26)$ & 0.001 \\
\hline
\end{tabular}

Abbreviation: PR, prevalence ratio.

a history of psychiatric illness, but no significant difference was found between their counterparts. These findings were concurrent with the findings of other studies. ${ }^{17,18}$ Similar results were found for suicidal attempts. But the association of suicidal attempts with employment status was found to be significant which was consistent with results from a study by Srivastava et al, ${ }^{17}$ which revealed that students and housewives outnumbered suicidal attempts compared with their counterparts. The possible reasons for higher suicidal attempts among unemployed could be due to the increased vulnerability to stressful life events, financial constraints, or underlining mental illness. ${ }^{19-21}$

One of the major findings of the present study is the higher risk of suicidal ideation and attempts among severe depressive patients. Out of 31 participants whose depression was in "very severe" level, most of them had suicidal ideation. These findings were in accordance with other studies conducted, ${ }^{16,18,22,23}$ suggesting that suicidal ideation is proportionate with the severity of depression. Considering the temporal association of suicidal attempts with the presence of depressive symptoms, 
Table 4 Intensity and reasons of suicidal ideation among individuals with major depressive disorder at a tertiary care hospital, Puducherry $(n=166)$

\begin{tabular}{|c|c|c|c|}
\hline Variable & Categories & $n$ & $\%$ \\
\hline \multirow[t]{25}{*}{ Intensity of ideation } & \multicolumn{3}{|l|}{ Frequency } \\
\hline & Less than once/week & 34 & 24.5 \\
\hline & Once/week & 39 & 2.1 \\
\hline & 2-5 times/week & 45 & 32.4 \\
\hline & Daily/almost daily & 14 & 10.1 \\
\hline & Many times/day & 8 & 5 \\
\hline & \multicolumn{3}{|l|}{ Duration } \\
\hline & Fleeting & 18 & 12.9 \\
\hline & For hours & 69 & 49.6 \\
\hline & Persistent & 32 & 23 \\
\hline & Most of the day/4-8 h & 12 & 8.6 \\
\hline & More than $8 \mathrm{~h}$ & 8 & 5.76 \\
\hline & \multicolumn{3}{|l|}{ Control } \\
\hline & Easily able to control & 25 & 25.2 \\
\hline & Control with little difficulty & 36 & 25.9 \\
\hline & Control with some difficulty & 23 & 16.6 \\
\hline & Control with lots of difficulty & 18 & 12.9 \\
\hline & Unable to control & 28 & 19.4 \\
\hline & \multicolumn{3}{|l|}{ Deterrents to acting } \\
\hline & Does not apply & 54 & 38.8 \\
\hline & Definitely stopped you & 44 & 31.7 \\
\hline & Probably stopped you & 20 & 14.4 \\
\hline & Uncertain that deterrents stopped you & 10 & 7.2 \\
\hline & Most likely did not stop you & 4 & 2.9 \\
\hline & Definitely did not stop you & 7 & 5 \\
\hline \multirow[t]{6}{*}{ Reasons for ideation } & Mostly to end or stop the pain & 16 & 11.5 \\
\hline & Completely to end or stop the pain & 7 & 5 \\
\hline & Equally to get attention, revenge, or reactions & 6 & 4.3 \\
\hline & Completely to get attention, revenge or reactions & 3 & 2.2 \\
\hline & Mostly to get attention, revenge, or a reaction & 1 & 0.7 \\
\hline & Does not apply & 107 & 76.4 \\
\hline
\end{tabular}

minimizing the duration of the depressed state would be an effective way for the prevention of suicidal acts. ${ }^{24}$

There are some potential limitations to this study. Since we interviewed the MDD patients who were on treatment, the effect of medicines might have influenced the assessment of MDD. There may be recall bias for suicidal behaviors, since participants were asked about their past. We have excluded major depressive patients with acute medical illnesses or those diagnosed as mentally retarded considering the feasibility of administering questionnaires. Also, since the sample size is low, the generalizability of the findings is limited. We used an open-ended questionnaire to capture the reasons for suicidal behavior, but a qualitative study in the form of an in-depth interview would have been a better design to get insight into those reasons.

Suicidal ideation and attempts were significantly high in MDD patients. Suicidal ideation and suicide attempts were significantly associated with MDD. Other than MDD, only employment status was associated with suicide attempts among major depressive patients. Identifying high-risk suicidal behavior and implementing effective preventive interventions are necessary among individuals with major depressive disorders.

\section{Note}

Deidentified individual participant data will not be available. This paper/study was not presented in any meeting or conference. This paper being submitted has not been published, simultaneously submitted, or already accepted for publication elsewhere.

\section{Ethical Approval}

The study protocol was reviewed and approved by the Nursing Research Monitoring Committee and Institute Ethics Committee. Written informed consent was taken before enrolling the study participants. 


\section{Funding}

None.

\section{Conflict of Interest}

None declared.

\section{References}

1 World Health Organization, Figures and Facts About Suicide. Geneva, Switzerland: World Health Organization; 1999

2 Dugas E, Low NCP, Rodriguez D, et al. Early predictors of suicidal ideation in young adults. Can J Psychiatry 2012;57(7):429-436

3 Gowda GS, Komal S, Sanjay TN, Mishra S, Kumar CN, Math SB. Sociodemographic, legal, and clinical profiles of female forensic inpatients in Karnataka: a retrospective study. Indian J Psychol Med 2019;41(2):138-143

4 Grover S, Raju VV, Sharma A, Shah R. Depression in children and adolescents: a review of indian studies. Indian J Psychol Med 2019;41(3):216-227

5 Subramaniam M, Abdin E, Seow ELS, Picco L, Vaingankar JA, Chong SA. Suicidal ideation, suicidal plan and suicidal attempts among those with major depressive disorder. Ann Acad Med Singapore 2014;43(8):412-421

6 Bhattacharjee A, Deb S. Suicidal tendencies among depressive patients. J Indian Acad Appl Psychol 2019;33:213-218

7 May AM, Klonsky ED, Klein DN. Predicting future suicide attempts among depressed suicide ideators: a 10-year longitudinal study. J Psychiatr Res 2012;46(7):946-952

8 Guan K, Fox KR, Prinstein MJ. Nonsuicidal self-injury as a time-invariant predictor of adolescent suicide ideation and attempts in a diverse community sample. J Consult Clin Psychol 2012;80(5):842-849

9 Wilkinson P, Kelvin R, Roberts C, Dubicka B, Goodyer I. Clinical and psychosocial predictors of suicide attempts and nonsuicidal self-injury in the Adolescent Depression Antidepressants and Psychotherapy Trial (ADAPT) Am J Psychiatry 2011; 168(5):495-501

10 Hamza CA, Stewart SL, Willoughby T. Examining the link between nonsuicidal self-injury and suicidal behavior: a review of the literature and an integrated model. Clin Psychol Rev 2012; 32(6):482-495

11 Klonsky ED, May AM, Glenn CR. The relationship between nonsuicidal self-injury and attempted suicide: converging evidence from four samples. J Abnorm Psychol 2013;122(1):231-237
12 Asarnow JR, Porta G, Spirito A, et al. Suicide attempts and nonsuicidal self-injury in the treatment of resistant depression in adolescents: findings from the TORDIA study. J Am Acad Child Adolesc Psychiatry 2011;50(8):772-781

13 Schneiderman N, Ironson G, Siegel SD. Stress and health: psychological, behavioral, and biological determinants. Annu Rev Clin Psychol 2005;1:607-628

14 Yoo HJ, Hong JP, Cho MJ, et al. Lifetime suicidal ideation and attempt in adults with full major depressive disorder versus sustained depressed mood. J Affect Disord 2016;203:275-280

15 Amudhan S, Gururaj G, Varghese M, et al. A population-based analysis of suicidality and its correlates: findings from the National Mental Health Survey of India, 2015-16. Lancet Psychiatry 2020;7(1):41-51

16 Werbeloff N, Markou M, Hayes JF, Pitman AL, Osborn DPJ. Individual and area-level risk factors for suicidal ideation and attempt in people with severe depression. J Affect Disord 2016; 205:387-392

17 Srivastava AS, Kumar R. Suicidal ideation and attempts in patients with major depression: Sociodemographic and clinical variables. Indian J Psychiatry 2005;47(4):225-228

18 Kwon A, Song J, Yook K-H, et al. Predictors of suicide attempts in clinically depressed Korean adolescents. Clin Psychopharmacol Neurosci 2016;14(4):383-387

19 Beautrais AL, Joyce PR, Mulder RT. Unemployment and serious suicide attempts. Psychol Med 1998;28(1):209-218

20 Jones SC, Forster DP, Hassanyeh F. The role of unemployment in parasuicide. Psychol Med 1991;21(1):169-176

21 Blakely TA, Collings SCD, Atkinson J. Unemployment and suicide. Evidence for a causal association? J Epidemiol Community Health 2003;57(8):594-600

22 HorwitzAG, CzyzEK, King CA.Predicting future suicide attempts among adolescent and emerging adult psychiatric emergency patients. J Clin Child Adolesc Psychol 2015;44(5):751-761

23 Mundt JC, Greist JH, Jefferson JW, Federico M, Mann JJ, Posner K. Prediction of suicidal behavior in clinical research by lifetime suicidal ideation and behavior ascertained by the electronic Columbia-Suicide Severity Rating Scale. J Clin Psychiatry 2013;74(9):887-893

24 Sokero TP, Melartin TK, Rytsälä HJ, Leskelä US, LesteläMielonen PS, Isometsä ET. Suicidal ideation and attempts among psychiatric patients with major depressive disorder. J Clin Psychiatry 2003;64(9):1094-1100 